\title{
Obstetric Referrals to a Tertiary Hospital in Northern Uganda - A One Year Experience
}

\author{
Elizabeth Nionzima ${ }^{1}$, Tom Charles Otim² \\ ${ }^{1}$ Department of Obstetrics and Gynaecology, Mulago Specialized Women and Neonatal Hospital, Kampala, Uganda. \\ ${ }^{2}$ Department of Obstetrics and Gynaecology, Lira University Hospital, Lira, Uganda.
}

\section{ABSTRACT}

\section{BACKGROUND}

Delay in referral adversely affects maternal and neonatal outcome. We wanted to review the obstetric referrals, source of referrals, appropriateness of referrals and document the maternal and perinatal outcomes in a tertiary hospital in northern Uganda.

\section{METHODS}

This is a secondary data analysis from case records. A descriptive study of 780 eligible obstetric referrals, with $\geq 28$ week's gestation, referred to the hospital for a period of 12 months were analysed with SPSS version 23 .

\section{RESULTS}

Obstetric referrals accounted for $16.3 \%$ (780/4799) of the total admissions in 2018, 43.8\% were from CEMNOC sites and 32.3\% from HC IVs, while 57\% from without Lira District, showing lacunae in the emergency obstetric care given at the HC IV levels and the districts hospital in the region. Majority or 93.5\% (729) were intrapartum admissions and $98.1 \%$ (715) of these had labour outcome recorded, showing the nature of referrals. Most common diagnosis at referral was labour or complications of labour and only $4.6 \%$ had other diagnoses. The diagnoses at the time of admission were normal labour (31.0\%); obstructed labour (25.1\%); prolonged labour (7.1\%). About 29.9\% presented with more than one medical/obstetric complications, and the most common one was obstructed labour, preeclampsia, IUFD and previous caesarean section scars. The outcome of the referred cases included $45.1 \%$ (327) vaginal delivery (either spontaneous or augmented), 54.4\% (396) caesarean section, 0.5\% (4) Caesarean hysterectomy, $3.1 \%$ (24) transferred out undelivered, $1.2 \%$ (09) missing outcome while the $3.6 \%$ (28) with medical conditions were managed and discharged. There were ten (10) maternal deaths among the referrals, during the study period and 3 were due to obstetric haemorrhage; and behind these there were many near misses which would provide valuable information on the quality of care at the peripheral facilities. $80.4 \%$ (627) were live babies, $10.5 \%$ (82) were FSB/MSB and $10 \%$ had APGAR score $\leq 5$ at 5 minutes of birth while $13.2 \%$ were of low birth weight.

\section{CONCLUSIONS}

A wide spectrum of complicated and uncomplicated obstetric cases was referred to this hospital and majority were unjustifiable as majority of the referred conditions could be managed at the lower CEMONC sites. Unavailability of Comprehensive Emergency Obstetric Care (CEMONC) was the most common reason for referrals, even where infrastructure and human resource where known to be available. Most common diagnosis at the time of referral was prolonged/obstructed labour. Even today, obstetric haemorrhage is the leading cause of maternal mortality while prolonged/obstructed labour contributed to the high neonatal mortality.

\section{KEY WORDS}

Obstetric Referrals, Maternal, Outcome, Foetal Outcome, Referral Sites, Tertiary
Corresponding Author: Elizabeth Nionzima,

Mulago Specialized Women and Neonatal Hospital, P.O Box 22081, Kampala, Uganda.

E-mail: enionzima@yahoo.com

DOI: $10.14260 / j e m d s / 2020 / 563$

How to Cite This Article:

Nionzima E, Otim TC. Obstetric referrals to a tertiary hospital in Northern Uganda- a one year experience. J Evolution Med Dent Sci 2020;9(36):2588-2592, DOI: $10.14260 /$ jemds/2020/563

Submission 19-05-2020,

Peer Review 27-07-2020,

Acceptance 04-08-2020,

Published 07-09-2020.

Copyright (c) 2020 JEMDS. This is an open access article distributed under Creative Commons Attribution License [Attribution 4.0 International (CC BY 4.0)] 


\section{BACKGROUND}

Urgently addressing malfunctions at any level in the referral levels will save lives. Timeliness and appropriateness of referral are a challenge to health care providers, since delay in referral adversely affects maternal and neonatal outcome.[1] Hence, identification and referral of high-risk pregnancies and obstetric emergencies are an integral part of maternal and child health services, to reduce the foetal and maternal morbidity and mortality. Appropriate and timely referral ensures continuity of care and inspires confidence in consumers in the health care system. ${ }^{[2]}$ Lira regional referral hospital receives a large number of obstetric referrals, but to date, little is documented about them. Maternal morbidity and mortality remain a major challenge to health systems worldwide and is an important focus for international development, thus the sustainable development goals.

Timely referral and intervention of high-risk pregnancies can reduce foetomaternal morbidity and mortality whereas unnecessary referrals increase workload on tertiary hospitals and also cause discomfort to pregnant women and relatives. Moreover, in obstetrics apparently normal is potentially abnormal and change can occur with frightening rapidity and requires experience to detect the patients at risk before emergency arises. Obstetrics is a one-way traffic. This demands eyes trained to see, hands skilled to feel, $[3,4]$ and brain disciplined to coordinate and act. Obstetric performance is assessed in terms of maternal and neonatal morbidity and early perinatal and maternal mortality. The known cases of maternal mortality in our set-up are namely haemorrhage, obstructed labour, sepsis, unsafe abortion and hypertensive disorders in pregnancy. The interaction of a variety of factors may contribute to limiting or delaying access to maternal health care services particularly emergency obstetric care when life threatening complications occur. Weaknesses and deficiencies in the health systems especially with regard to referral linkages may affect access to emergency obstetric care and negatively influence maternal and foetal outcomes.

Lira Regional Referral Hospital is a tertiary institution that receives most of these emergency obstetric referrals. Emergency obstetric care (EmOC) refers to elements of obstetric care needed or management of complications during pregnancy, delivery and postpartum period, skilled personnel, equipment and support services. EmOC services are of paramount importance in reducing maternal mortality and morbidity.[2,5] It is still recommended to electively refer pregnant woman with previous caesarean section, breech presentation, transverse lie, multiple gestation, hypertension and severe anaemia for delivery before any complication arise to a health care centre where all the facilities to deal with the complications are available. With this background, present study was undertaken to evaluate the pattern of obstetric cases referred to tertiary hospital and maternal outcomes amongst referred case.

\section{METHODS}

This is a secondary data analysis from case records; a descriptive study of 780 eligible obstetric referrals, $\geq 28$ week's gestation, referred to the hospital for a period of 12 months were analysed with SPSS version 23. This descriptive study was undertaken at Department of Obstetrics \& Gynaecology, Lira Regional Referral Hospital from $1^{\text {st }}$ January 2018 to $31^{\text {st }}$ December 2018 after attaining institutional ethical clearance.

The objectives of this study were to review the obstetric referrals, source of referrals; the appropriateness of referrals and document the maternal and perinatal outcomes. Data was from 4799 admissions drawn from the integrated maternity register. The study population consisted of all (780) cases of obstetric referrals from periphery health units at 28 weeks or more, requiring emergency obstetric care. The total number of deliveries during this period were 4313 out of the 4799 total admissions. Data was obtained from referral sheets, patient case notes, Ward registers and theatre records.

Excluded cases included postpartum referrals; selfreferrals and referred cases less than 28 weeks of gestation. The outcome measures were level of referring unit, $\mathrm{C} / \mathrm{S}$, maternal and foetal outcome which was retrieved from the case notes; APGAR score less than 7 at 5 minutes and indication for $\mathrm{C} / \mathrm{S}$. Descriptive Data analysis statistics like percentages was done using Statistical Package for Social Sciences (SPSS) software version 23.

\section{RESULTS}

\section{Demographics of Obstetric Referrals}

The proportion of obstetric referral cases to the tertiary care center was $16.3 \%$ (780/4799) of the total admissions which compares with other studies,[4] $97.4 \%$ of the referred cases had their age recorded and the mean age of the patients was 24.3 years while the age ranged between 14 years to 48 years. Maximum number of cases in the study were in the age group 20-29 years comprising 48\%, while most mothers were in the age group $<24$ years as this comprised $59.7 \%$. Concerning the pregnancy status, 96.4 were intrapartum, $0.3 \%$ postpartum and the rest antepartum (Table 4 ). The majority of the referral cares were Primipara (40.4\%). The number of referrals decreased with increasing gravidity irrespective of the level of the facility. In this study, we found that $44.0 \%$ of the patients were primigravidas, which is comparable to other studies. $[5,6]$

\begin{tabular}{|c|c|c|c|c|c|c|}
\hline \multirow{2}{*}{ Gravidity } & \multicolumn{6}{|c|}{ Aggregated Age in Years } \\
\hline & $</=19$ & $20-29$ & $30-39$ & $>/=40$ & Missing & Total \\
\hline G1 & $180(26.5 \%)$ & $98(14.4 \%)$ & $3(0.4 \%)$ & $1(0.1 \%)$ & $3(0.4 \%)$ & $285(42.0 \%)$ \\
\hline G2-4 & $16(2.4 \%)$ & $169(24.9 \%)$ & $32(4.7 \%)$ & $1(0.1 \%)$ & $5(0.7 \%)$ & $223(32.8 \%)$ \\
\hline G5-9 & $0(0.0 \%)$ & $37(5.4 \%)$ & $78(11.5 \%)$ & $9(1.3 \%)$ & $6(0.9 \%)$ & $130(19.1 \%)$ \\
\hline$>/=\mathrm{G} 10$ & $0(0.0 \%)$ & $0(0.0 \%)$ & $4(0.6 \%)$ & $6(0.9 \%)$ & $0(0.0 \%)$ & $10(1.5 \%)$ \\
\hline Missing & $0(0.0 \%)$ & $22(3.2 \%)$ & $8(1.2 \%)$ & $0(0.0 \%)$ & $1(0.1 \%)$ & $31(4.6 \%)$ \\
\hline Total & $\begin{array}{c}196 \\
(28.9 \%)\end{array}$ & $\begin{array}{c}326 \\
(48.0 \%)\end{array}$ & $\begin{array}{c}125 \\
(18.4 \%)\end{array}$ & $\begin{array}{c}17 \\
(2.5 \%)\end{array}$ & $\begin{array}{c}15 \\
(2.2 \%)\end{array}$ & $\begin{array}{c}679 \\
(100.0 \%)\end{array}$ \\
\hline & & 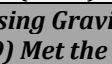 & 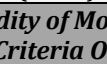 & & & $A g$ \\
\hline
\end{tabular}

\section{Source of Referrals}

Four hundred twelve (52.8\%) of the mothers were refereed in from various health centres outside Lira district and the majority were from Government facilities,[7] that is HC II, HC III, HC IV and hospitals. The bulky of referrals came from HC 
III which is the Basic obstetric emergency care unit, thus bypassing the immediate comprehensive emergency health centre IVs; and referrals from HC III also contributed to the high number of $\mathrm{C} /$ Section indicating appropriateness of referrals (Table II). Mothers who lost the reproductive potential soon after admission were from the same HC IIIs. Half of the referrals had emergency Caesarean section.

In this study, more than $1 / 3(44.5 \%)$ of the referrals were from comprehensive emergency obstetric and Neonatal Care (CEMONC) sites; that is, HC IVs, Medical centers and hospitals. showing a lacuna in the emergency obstetric care given at the CEMONC sites. As many as $53.3 \%$ of the referrals were directly from lower centers, hence, bypassing the intermediate levels of the referral chain. Although sometimes bypassing the intermediate levels of care is necessary if the desired facility is available only at the higher centers, but such reasons do not account for such a higher figure of 53.5\% in this study, $[2,1]$ and in line with other studies. Majority of the mothers stayed at the facility for less than 7 days $(705$, 91.0\%), 59 (7.6\%) between 7-14 days and while less than $2 \%$ stayed for more than 14 days. The minimum duration of stay was one (1) day that comprised $33.2 \%$, mean duration of stay was 3.45 days and the maximum was 46 days with a range of 45 days.

\begin{tabular}{|c|c|c|c|c|c|c|c|}
\hline & \multicolumn{7}{|c|}{ Mode of Delivery } \\
\hline & is & 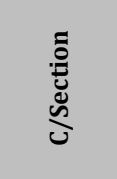 & 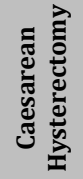 & 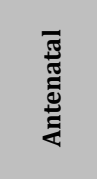 & 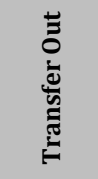 & 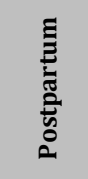 & 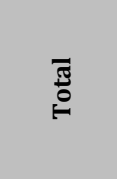 \\
\hline Level II & $8(1.0 \%)$ & $7(0$. & $0(0.0 \%)$ & $0(0.0 \%)$ & $0(0.0 \%)$ & $0(0.0 \%)$ & $15(1$. \\
\hline Level III & $171(21.9 \%)$ & $202(25.9 \%)$ & $4(0.5 \%)$ & $11(1.4 \%)$ & $13(1.7 \%)$ & $0(0.0 \%)$ & $401(51.4 \%)$ \\
\hline Level IV & $112(14.4 \%)$ & $128(16.4 \%)$ & $0(0.0 \%)$ & $8(1.0 \%)$ & $5(0.6 \%)$ & $1(0.1 \%)$ & $254(32.6 \%)$ \\
\hline Hospital & $8(1.0 \%)$ & $15(1.9 \%)$ & $0(0.0 \%)$ & $1(0.1 \%)$ & $2(0.3 \%)$ & $0(0.0 \%)$ & $26(3.3 \%)$ \\
\hline $\begin{array}{l}\text { Medical } \\
\text { Centre }\end{array}$ & $24(3.1 \%)$ & $35(4.5 \%)$ & $0(0.0 \%)$ & $6(0.8 \%)$ & $2(0.3 \%)$ & $0(0.0 \%)$ & $67(8.6 \%)$ \\
\hline Others & $4(0.5 \%)$ & $9(1.2 \%)$ & $0(0.0 \%)$ & $2(0.3 \%)$ & $1(0.1 \%)$ & $1(0.1 \%)$ & $17(2.2 \%)$ \\
\hline Total & $\begin{array}{c}327 \\
(41.9 \%)\end{array}$ & $\begin{array}{c}396 \\
(50.8 \%)\end{array}$ & $\begin{array}{c}4 \\
(0.5 \%)\end{array}$ & $\begin{array}{c}28 \\
(3.6 \%)\end{array}$ & $\begin{array}{c}23 \\
(2.9 \%)\end{array}$ & $\begin{array}{c}2 \\
(0.3 \%)\end{array}$ & $\begin{array}{c}780 \\
(100.0 \%)\end{array}$ \\
\hline & & II. Dis & tin & Case & remern & to & \\
\hline
\end{tabular}

\section{Indication for Obstetric Referrals}

Table III presents the main diagnoses at referral by the referring units and the diagnosis at admission at the tertiary unit as recorded in the integrated register or operation book. In this study, 93.5\% (729) of the cases were admitted in labour or with labour complications; $95.1 \%$ had referral notes and the reason for referral recorded while 98.1\% (715) of these had labour outcome recorded.

Most common diagnosis for referral was labour or intrapartum complications and only $4.6 \%$ had other diagnoses. The most common reasons for referral were prolonged labour (46.8\%), obstructed labour (10.0\%), APH (5.0\%), Hypertensive disorders in pregnancy (3.8\%), Previous C/S scar (4.0\%). The diagnoses at the time of admission were normal labour $(31.0 \%)$; obstructed labour (25.1\%); prolonged labour (7.1\%). Prolonged and obstructed labour were the most frequent registered diagnoses while a sizeable number of cases were referred with no identifiable reason. Many of the referrals with prolonged labour turned out as normal labour or obstructed labour; while $29.9 \%$ presented with more than one obstetric diagnosis / complication. Among others were retained twin, PPH, Ruptured uterus, Malaria in pregnancy, post-operative sepsis, Oligohydramnios/ polyhydramnios. IUFD, and previous caesarean section scars. Although anaemia is prevalent in pregnant women, only $0.4 \%$ were referred due to anaemia.

\begin{tabular}{|c|c|c|c|}
\hline $\begin{array}{l}\text { Reasons for } \\
\text { Referral (A) }\end{array}$ & Frequency & $\begin{array}{c}\text { Diagnosis on } \\
\text { Admission (B) }\end{array}$ & Frequency \\
\hline Prolonged Labour & $365(46.8 \%)$ & Obstructed Labour & $198(25.4 \%)$ \\
\hline Obstructed Labour & $78(10.0 \%)$ & Normal Labour & $173(22.2 \%)$ \\
\hline APH & $39(5.0 \%)$ & $2^{\text {nd }}$ stage of labour & $78(10.0 \%)$ \\
\hline Hypertensive Disorders & $30(3.8 \%)$ & Prolonged Labour & $54(6.9 \%)$ \\
\hline Preterm Labour & $21(2.7 \%)$ & Contracted Pelvis & $31(4.1 \%)$ \\
\hline Previous C/S Scar & $32(4.0 \%)$ & APH & $30(3.8 \%)$ \\
\hline Mal-Presentation & $23(3.0 \%)$ & Preeclampsia/Eclampsia & $27(3.5 \%)$ \\
\hline IUFD & $19(2.4 \%)$ & Malpresentation/Malposition & $21(2.7 \%)$ \\
\hline UTI & $15(1.9 \%)$ & Foetal distress & $19(2.4 \%)$ \\
\hline PROM & $14(1.8 \%)$ & Preterm labour & $19(2.4 \%)$ \\
\hline Multiple Pregnancy & $14(1.8 \%)$ & Previous c/s scar & $11(1.4 \%)$ \\
\hline Contracted Pelvis & $12(1.5 \%)$ & UTI & $09(1.2 \%)$ \\
\hline Malaria & $9(1.2 \%)$ & Arm prolapse & $09(1.2 \%)$ \\
\hline Foetal Distress & $9(1.2 \%)$ & Cord prolapse & $08(1.0 \%)$ \\
\hline Others & $100(17.9 \%)$ & Others & $102(11.8 \%)$ \\
\hline Total Referrals & $780(100.0 \%)$ & Total & $780(100 \%)$ \\
\hline \multicolumn{4}{|c|}{ Table III. Distribution of Cases According to } \\
\hline
\end{tabular}

\section{Outcome of Obstetric Referrals}

Tables IV show the distribution of mode of delivery and neonatal outcomes in $\mathrm{C} / \mathrm{S}$ and normal delivery cases. Caesarean section rate was $54.4 \%$ in the referred cases who delivered, which is comparable to other studies in the region, $[7,8]$ Out of that majority only one was done as elective caesarean section. The outcome of the referred cases included: $45.1 \%$ (327) vaginal delivery (either spontaneous or augmented); $0.6 \%$ (04) Caesarean hysterectomy, $2.9 \%$ (23) were transferred out undelivered due to logistical issues, $0.5 \%$ (04) were postpartum. Those did not deliver, 3.6\% (28) had medical conditions were managed conservatively and discharged while $3.1 \%$ (24) were transferred out undelivered due to logistical issues in the operating theatre.

\begin{tabular}{|ccccccc|}
\hline $\begin{array}{c}\text { Mode of } \\
\text { Delivery }\end{array}$ & $\begin{array}{c}\text { Live } \\
\text { Birth }\end{array}$ & $\begin{array}{c}\text { Fresh } \\
\text { Still } \\
\text { Birth }\end{array}$ & $\begin{array}{c}\text { Macerated Neonatal Missing } \\
\text { Still Birth }\end{array}$ & Death & Outcome & Total \\
SVD & $280(38.5 \%)$ & $19(2.6 \%)$ & $17(2.3 \%)$ & $06(0.8 \%)$ & $06(0.8 \%)$ & $328(45.1 \%)$ \\
C/Section & $345(47.4 \%)$ & $39(5.4 \%)$ & $02(0.3 \%)$ & $07(0.9 \%)$ & $03(0.4 \%)$ & $396(54.4 \%)$ \\
C/S & $02(0.3 \%)$ & $02(0.3 \%)$ & $00(0.0 \%)$ & $00(0.0 \%)$ & $00(0.0 \%)$ & $04(0.5 \%)$ \\
Hysterectomy & $\mathbf{6 2 7}$ & $\mathbf{6 0}$ & $\mathbf{1 9}$ & $\mathbf{1 3}$ & $\mathbf{0 9}$ & $\mathbf{7 2 8}$ \\
Total & $\mathbf{6 6 . 1 \% )}$ & $(\mathbf{8 . 2 \% )}$ & $\mathbf{( 2 . 6 \% )}$ & $\mathbf{( 1 . 8 \% )}$ & $\mathbf{( 1 . 2 \% )}$ & $\mathbf{( 1 0 0 \% )}$ \\
\hline \multicolumn{7}{|c|}{ Table IV. Distribution of Obstetric Referral According to } \\
Mode of Delivery and Foetal Outcome
\end{tabular}

There were 10 maternal mortalities among the referrals as follows: 3 followed normal delivery but admitted with intrauterine Foetal death, five after $\mathrm{C} /$ Section for indication including eclampsia and obstructed labour, one after hysterectomy for ruptured uterus and one died undelivered admitted with aspiration pneumonia admitted unconscious. This contributed to $1.3 \%$ of the total referrals. Behind these deaths, there were many near misses which would provide valuable information on the quality of care at the periphery facilities and tertiary facility. $6.2 \%$ of mothers had at least one recorded postpartum complication. Among the maternal morbidities included Wound sepsis, Puerperal sepsis (22), Burst abdomen (6) with repeat laparotomy, loss of reproductive potential due to postpartum hysterectomy (4). In the present study, $3.1 \%$ of referred cases were transferred 
out due to lack of operating theatre services. The government should take measures to improve health infrastructure facilities, at tertiary centres to reduce the burden on the mothers of multiple referrals.

\begin{tabular}{|cccc|}
\hline $\begin{array}{c}\text { Indication for } \\
\text { C/Section }\end{array}$ & Yes & No & $\begin{array}{c}\text { Total } \\
\text { Operations }\end{array}$ \\
Obstructed Labour & $80(20.1 \%)$ & $108(27.1 \%)$ & $188(47.1 \%)$ \\
Prolonged Labour & $13(3.3 \%)$ & $24(6.0 \%)$ & $37(9.3 \%)$ \\
CPD & $14(3.5 \%)$ & $19(4.9 \%)$ & $33(8.3 \%)$ \\
Severe PET & $8(2.0 \%)$ & $11(2.8 \%)$ & $19(4.8 \%)$ \\
Foetal Distress & $9(2.3 \%)$ & $9(2.3 \%)$ & $18(4.5 \%)$ \\
APH & $9(2.3 \%)$ & $9(2.3 \%)$ & $18(4.5 \%)$ \\
Malpresentation & $12(3.0 \%)$ & $15(3.8 \%)$ & $29(7.3 \%)$ \\
Prolonged Prom & $7(1.8 \%)$ & $4(1.0 \%)$ & $11(2.8 \%)$ \\
Prematurity & $1(0.3 \%)$ & $7(1.8 \%)$ & $8(2.0 \%)$ \\
Repeat C/Section & $13(3.3 \%)$ & $4(1.0 \%)$ & $17(4.3 \%)$ \\
Breech & $5(1.3 \%)$ & $4(1.0 \%)$ & $9(2.3 \%)$ \\
Ruptured Uterus & $0(0.0 \%)$ & $4(1.0 \%)$ & $4(1.0 \%)$ \\
Others & $3(0.8 \%)$ & $6(1.5 \%)$ & $2(2.3 \%)$ \\
Total & $\mathbf{1 7 4 ( 4 3 . 6 \% )}$ & $\mathbf{2 2 5}(54.4 \%)$ & $\mathbf{3 9 9}(100.0 \%)$ \\
\hline Table V. Referrals from Comprehensive Obstetric Emergency Sites \\
\multicolumn{4}{c}{ and Indication for Operation } \\
\hline
\end{tabular}

\section{Foetal Outcome}

Neonatal outcomes were 86.1\% (627) live babies, 8.1\% (60) FSB, $2.6 \%$ (19) MSB, 1.8\% (13) early neonatal deaths while $10 \%$ had APGAR score $\leq 5$ at 5 minutes of birth and $13.2 \%$ of the recorded weights were low birth. Of the total live births, $18.2 \%$ (142) were admitted to NICU.

\begin{tabular}{|c|c|c|c|c|c|c|}
\hline & & Apga & ar Score & & & \\
\hline & $0-1$ & $2-4$ & $5-7$ & 8-10 & $\begin{array}{c}\text { Missing } \\
\text { Score }\end{array}$ & Total \\
\hline Live Births & $0(0.0 \%)$ & $43(5.9 \%)$ & $156(21.4 \%)$ & $423(58.1 \%)$ & $5(0.7 \%)$ & 627(86.1\%) \\
\hline FSB & $60(8.2 \%)$ & $0(0.0 \%)$ & $0(0.0 \%)$ & $0(0.0 \%)$ & $0(0.0 \%)$ & $60(8.2 \%)$ \\
\hline MSB & $19(2.6 \%)$ & $0(0.0 \%)$ & $0(0.0 \%)$ & $0(0.0 \%)$ & $0(0.0 \%)$ & $19(2.6 \%)$ \\
\hline END & $0(0.0 \%)$ & $11(1.5 \%)$ & $2(0.3 \%)$ & $0(0.0 \%)$ & $0(0.0 \%)$ & $13(1.8 \%)$ \\
\hline $\begin{array}{c}\text { Missing } \\
\text { Outcome }\end{array}$ & $0(0.0 \%)$ & $0(0.0 \%)$ & $0(0.0 \%)$ & $0(0.0 \%)$ & $9(1.2 \%)$ & $9(1.2 \%)$ \\
\hline Total & $79(10.9 \%)$ & $54(7.4 \%)$ & $158(21.7 \%)$ & $423(58.1 \%)$ & $14(1.9 \%)$ & $728(100.0 \%)$ \\
\hline Table & Foetal 0 & Dutcom & f Labour & in Relati & to $A P G$ & IR Score \\
\hline
\end{tabular}

\section{DISCUSSION}

The importance of referral in obstetric emergencies is related to the unpredictability of pregnancy complications and their potential to rapidly progress to become severe and life threatening. For example, haemorrhage can lead to the death of the woman and her baby in minutes or hours. ${ }^{[9,4]}$ Lira Regional Referral hospital is a tertiary care hospital, where complicated obstetric cases are referred from various peripheral primary and private health centers within and the surrounding districts. The proportion of obstetric referrals to our tertiary care institute accounted for $16.3 \%{ }^{[4]}$ of the total admissions. Umesh Sabale, Alka Murlidhar Patankar.[10] in their study "Study of Maternal and Perinatal Outcome in Referred Obstetrics Cases" 24.16\% were referred cases.

The studied population was predominantly young with $59.7 \%$ below 25 years of age which is comparable to the above authors and other studies ${ }^{[10]}$ and a mean age was 24.3 and a wide range of 14 to 48 years. Similar results were seen in a study conducted in Africa where the mean age was 24.1 years ${ }^{[4,10.3]}$ Most of the referred women were between 20-30 years $(48 \%)^{[3,4]}$ with $28.9 \%$ below 20 years and only $2.5 \%$ above 40 years. Majority of referred cases (44\%) were prime gravida as in other studies ${ }^{[4]}$ and $56 \%$ distributed between gravida 2 to 12 . The number of referrals reduced with increasing age and gravidity (Table I). The minimum number of stay at the facility was one day with a range of 45 days. [7]

Most of the patients in our study were referred from Health center IIIs (51.4\%) ${ }^{[1]}$ and HC IVs $(32.3 \%)$ as seen in table 2 from within and various neighbouring districts; indicating that the major burden of referrals and majority of the patients referred were in labour or with labour complications (Table 4). In a similar observational study conducted in Gujarat, most common referral was during the intra-partum period similar to our study.[3,7,12],[7,11] In this study, $41.9 \%$ of the referrals were admitted with conditions that could be managed in the referring units as seen from the mode of delivery (Table II). This could be a reflection of the quality of obstetric care at the referring facilities with reference to the availability of signal functions of a Basic Emergency Obstetric and Neonatal Care (EmONC).

Unlike in other studies,[2,5,7,11] where hypertensive disorders and other medical conditions were the major cause of referral to tertiary care hospital, the most common diagnosis made at arrival of women referred in this study were obstructed labour followed by normal labour that do not require tertiary care but could also be prevented (Table III). This indicates that many of the referrals were unjustified. Proper Monitoring of labour using a partograph can prevent morbidity from abnormal labour or prolonged labour, which is preventable cause of maternal and perinatal morbidity and mortality.

In this present study, $41.9 \%$ of the referred cases had vertex delivery either spontaneous or augmented. The referrals had an overall caesarean rate of $50.8 \%$, while the average emergency caesarean section rate was $26.3 \%$ in all the women admitted to the labour ward in the same period; which was comparable to other studies, ${ }^{[8]}$ and $51.4 \%$ needed some surgical interventions. It is noted in this study that emergency obstetric referrals had a higher caesarean rate in comparison to the total population admitted to labour ward indicating that referrals are a special group of patients who need timely and appropriate interventions to prevent adverse maternal and foetal outcomes. The most common indication of caesarean section was obstructed labour (Table V).

In this study, the total number of births were 719 (96.1\%) while 28 (3.6\%) were discharged undelivered and 24 (3.1\%) who needed surgical interventions were transferred out due to logistical problems like lack of theatre supplies. Of these, the total number of live births and discharged alive were 627 (80.4\%), 13 neonatal deaths and 79 (10.1\%) were still births comparable with other studies.[12,13] The cause of death were mostly complications related to severe asphyxia. In our study, $30.1 \%$ of babies had 5 -minute score of less $\leq 7 .{ }^{[8]}$

There were 10 maternal deaths in this study, and the leading cause was obstetric haemorrhage. And 8 of these died within 6 hours of admission. This shows a delay in referral of complicated cases from the peripheral health centers, which could be due to lack of transport facilities, inadequate skills by health personnel to diagnose emergencies and patient attitude towards referral. Some cases arrived two days from the time of referral. The leading cause of maternal mortality in this study was obstetric haemorrhage and complications of obstructed labour. 
Many of the patients referred did come with missing information on the referral letter like the treatment given, duration of labour, duration of stay at the referring facility and time of referral or even the reason for referral. This incomplete documentation can lead to delay in the provision of emergency obstetric care or the mismanagement of patients.

\section{CONCLUSIONS}

A wide spectrum of complicated and non-complicated obstetric cases were referred to the hospital. $44.2 \%$ of referrals were unjustified and preventable in our study as they came from CEMONC sites where the required infrastructure or manpower was known to be available while some referred with the diagnosis of non-progress of labour or obstructed labour did not have any evidence of the same. A number of referrals were directly from lower centers to the tertiary institution; bypassing the health centers IVs, the primary CEMONC center. Women referred had higher caesarean section rate than the general population of admitted women, indicating that the referral system is capable of identifying high risk pregnancies, but also indicates underutilization of the CEMONC facilities. More than half of those who delivered required surgical intervention. Timely referrals with detailed referral slips might help in early and optimal intervention thereby reducing maternal and perinatal mortality. Moreover, a structured referral system would help both patient and doctor in providing essential lifesaving care.

\section{Recommendations}

Peripheral health care system needs to be strengthened as many of the referrals were preventable since they were due to complications of labour and the reasons for referral was further management, which indicates the need for equipping these centers with the required human resource and supplies. But where these facilities do not exist or are inadequate, the practice of early referral for better maternal and neonatal outcome should be the norm. All in all, unnecessary referrals put significant burden on the resources at referral center and hence, should be discouraged with strict referral guidelines.

Financial or Other Competing Interests: None.

\section{REFERENCES}

[1] Samiksha S, Pat D, Oona MC, et al. Referrals between public sector health institutions for women with obstetric high risk, complications, or emergencies in India- a systematic Review. PLoS ONE 2016;11(8):e0159793.

[2] Aggarwal N, Singla R, Dhaliwal L, et al. Audit of emergency obstetric referrals- a pilot study from tertiary care centre of North India. Bangladesh J Obstet Gynecol 2015;30(1)25-9.

[3] Narsaria K, Mukhopadhya P, Kyal MP, et al. A study of obstetric referrals-one year experience at a tertiary care centre in West Bengal. HECS Int J Com Health and Med Res 2017;3(3):32-6.

[4] Gupta PR, Chaudhari SN, Gonnade NV. Maternal and foetal outcome in referred patients to tertiary care center. Scholars Journal of Applied Madical Science 2016;4(5C):1624-31.

[5] Prakriti G, Jyoti B, Niketa C. Pattern of obstetric cases referred at tertiary care centre in central India. Int J Reprod Contracept Obstet Gynecol 2017;6(6):2370-4.

[6] Rohit GP, Nitin CS, Vasantrao GN. Maternal and foetal outcome in referred patients to tertiary care center. Sch J Appl Med Sci 2016;4(5C)1624-31.

[7] Maskey S. Obstetric referrals to a tertiary teaching hospital of Nepal. NJOG 2015;19(1):52-6.

[8] Sørbye IK, Vangen S, Oneko 0, et al. Caesarean section among referred and Self-referred birthing women: a cohort study from a tertiary hospital, northern Tanzania. BMC Pregnancy \& Childbirth 2011;11:55.

[9] Akaba GO, Ekele BA. Maternal and foetal outcomes of emergency obstetric referrals to a Nigerian teaching hospital. Trop Doct 2018;48(2)132-5.

[10] Julia H, Lovney K, Margaret A, et al. The effectiveness of emergency obstetric referral interventions in developing country settings: a systematic review. PLoS Medline 2012;9(7):e1001264.

[11] Patel HC, Singh BB, Moitra M, et al. Obstetric referrals: scenario at a primary health centre in Gujarat. Natl J Community Med 2012;3(4)711-4.

[12] Sorbye K, Vangen S, Oneko O, et al. Caesarean section among referred and self- referred barthing women: a cohort study from a tertiary hospital, north Eastern Tanzania. BMC Pregnancy and Childbirth 2011;11(55)

[13] Umesh S, Patankar AM. Study of maternal and perinatal outcome in referred obstetric cases. J Evolution Med Dent Sci 2015;4(26):4448-55.

[14] Shilpa SB, Anand PK. Study of obstetric referrals to teaching institute: original article. Indian J Appl Res 2013;3(7):469-71. 